\title{
$\mathrm{COSCi}_{\text {ech }}$ Jurnal Computer Science and Information Technology (CoSciTech)
}

\section{Sistem informasi kaji cepat bencana kebakaran BPBD provinsi DKI jakarta menggunakan java netbeans}

Firman Anggoro *1, Dian Nazelliana ${ }^{2}$, Nia Damayanti ${ }^{3}$

Email: ${ }^{1}$ anggoro.firman@gmail.com, ${ }^{2}$ dosen.dian@gmail.com, ${ }^{3}$ nia88damayanti@gmail.com

${ }^{123}$ Teknik Informatika, Fakultas Teknik dan Ilmu Komputer, Universitas Indraprasta PGRI

Diterima: 20 Oktober 2021 | Direvisi: - | Disetujui: 16 Desember 2021

(C)2021 Program Studi Teknik Informatika Fakultas Ilmu Komputer,

Universitas Muhammadiyah Riau, Indonesia

\begin{abstract}
Abstrak (10pt, tebal, dan rata kiri kanan)
Sistem informasi kaji cepat bencana kebakaran BPBD Provinsi DKI Jakarta dibangun agar agar sistem informasi pengolahan data kebencanaan kebakaran di BPBD Provinsi DKI Jakarta dapat berjalan secara tepat, efektif dan efisien. Pendekatan kasus di BPBD Provinsi DKI Jakarta menggunakan metode deskriptif, yaitu suatu metode dengan tujuan untuk membuat gambaran secara sistematis, faktual, dan akurat mengenai fakta-fakta dan sifat - sifat pada suatu objek penelitian tertentu. Pada tahap pertama, penulis melakukan pengumpulan data dan bahan yang diperlukan terlebih dahulu, dan pada tahap berikutnya penulis mengolah dan membahas sampai pada suatu kesimpulan. Sistem informasi kaji cepat kebakaran yang dibangun penulis dengan menggunakan bahasa pemrograman Java dan database Mysql yang dapat memberikan kemudahan dalam hal pengolahan data kebakaran secara cepat dan tepat dibandingkan dengan sistem sebelumnya yang masih menggunakan sistem manual, memberikan perhitungan otomatis yang memudahkan dalam memproses pemenuhan kebutuhan dasar korban kebakaran, juga mampu menghasilkan laporan kejadian kebakaran diantaranya laporan data bencana, data pengungsi, perhitungan kebutuhan dasar dan data penanganan kebakaran. Sebelum sistem baru dilaksanakan, sebaiknya bagian Bidang Kedaruratan dan Logistik harus diberikan penjelasan dengan baik, terlebih dahulu mengenai proses kerja sistem yang akan diterapkan sehingga tidak terjadi kekeliruan. Serta perlu dilakukan pelatihan penggunaan sistem tersebut terhadap bagian distribusi dalam sistem ini agar mereka dapat mengetahui dan memahami cara kerja sistem yang baru.
\end{abstract}

Kata kunci: sistem, kaji cepat, kebakaran, bencana, pelaporan

\section{Information system for rapid assessment of fire disaster BPD DKI jakarta province using java netbeans}

Abstract (10pt, italic, tebal, dan rata kiri kanan)

The information system for rapid assessment of the BPBD of DKI Jakarta Province was built so that the fire disaster data processing system at the BPBD of DKI Jakarta Province could run precisely, effectively and efficiently. The case approach at BPBD DKI Jakarta Province uses a descriptive method, which is a method with the aim of making a systematic, factual, and accurate description of the facts and characteristics of a particular research object. In the first stage, the writer collects the data and materials needed first, and in the next stage the writer processes and discusses to arrive at a conclusion. The fire rapid assessment information system built by the author uses the Java programming language and Mysql database which can provide previous convenience in terms of processing fire data quickly and precisely compared to systems that still use manual systems, providing automatic calculations that make it easier to meet the basic needs of fire victims, and also able to generate reports of fire events, disaster reports, refugee data, calculation of basic needs and handling of fire data. Before the new system is implemented, it is recommended that the Emergency and Logistics Division be given a good explanation first, regarding the work process that will be implemented so that no incident occurs. And it is necessary to conduct training on the use of the system for the distribution section of this system so that they can know and understand how the new system works.

Keywords: system, rapid assessment, fire, disaster, reporting 


\section{Pendahuluan}

Saat ini teknologi telah berkembang dengan pesat, banyak pekerjaan yang dilakukan setiap harinya oleh suatu instansi maupun organisasi berjalan dengan baik apabila menggunakan komputer, teknologi informasi dan aplikasi yang dibangun untuk memudahkan suatu instansi dalam menjalankan pekerjaan tersebut. Sistem yang dibangun dengan baik dapat memberikan dampak positif terhadap pelayanan yang diberikan oleh organisasi atau instansi, salah satunya yang terjadi di Badan Penanggulangan Bencana Daerah (BPBD) Provinsi DKI Jakarta.

Badan Penanggulangan Bencana Daerah (BPBD) Provinsi DKI Jakarta merupakan suatu instansi pemerintah yang mempunyai tugas untuk menangani bencana baik dari pra bencana (faktor kesiapsiagaan), saat bencana (kondisi darurat bencana), pasca bencana (fase pemulihan). Saat ini proses pendataan kebencanaan BPBD Provinsi DKI Jakarta masih lambat disebabkan proses yang dilakukan masih secara manual. Dalam fakta di lapangan, didapatkan data tersebut kurang akurat dan waktu yang dibutuhkan cukup lama untuk pengolahan data.

Dengan pertimbangan dan permasalah di atas, maka perlu dibangun dan diterapkan suatu sistem informasi yang mengelola data bencana kebakaran di BPBD Provinsi DKI Jakarta menggunakan Bahasa Java dan MySQL sebagai database server agar sistem informasi pengolahan data kebencanaan kebakaran di BPBD Provinsi DKI Jakarta dapat berjalan secara tepat, efektif dan efisien.

Tujuan dari penelitian ini adalah embuat sistem informasi pengolahan data bencana kebakaran pada BPBD Provinsi DKI Jakarta dengan berbasis Android, mempermudah Tim Kaji Cepat bencana kebakaran dalam mengirimkan data kaji cepat di lapangan, mengelola informasi yang akurat dalam hal informasi yang berkaitan dengan bencana kebakaran yang terjadi.

\section{Metode Penelitian}

Pendekatan kasus di BPBD Provinsi DKI Jakarta menggunakan metode deskriptif, yaitu suatu metode dengan tujuan untuk membuat gambaran secara sistematis, faktual, dan akurat mengenai fakta-fakta dan sifat - sifat pada suatu objek penelitian tertentu. Pada tahap pertama penulis melakukan pengumpulan data dan bahan yang diperlukan terlebih dahulu, dan pada tahap berikutnya penulis mengolah dan membahas sampai pada suatu kesimpulan yang pada akhirnya dapat dibuat suatu laporan untuk melampirkan semua kegiatan yang dikerjakan selama dilakukannya penelitian di BPBD.

Penulis bukan hanya mencari dan mengumpulkan data, tetapi juga langsung melakukan klasifikasi terhadap data tersebut, mengolah dan menganalisa data, membangun hipotesis menjadi teori serta menulis draft kasar laporannya dari waktu ke waktu.

Metode pengumpulan data yang digunakan antara lain menggunakan studi pustaka dengan mengumpulkan beberapa bahan teori dari buku sumber yang berhubungan dengan masalah yang diteliti untuk mencocokkan antara fakta yang terjadi dengan aspekaspek yang ada dalam pembangunan aplikasi dam metode selanjutnya yaitu menggunakan metode studi lapangan untuk mendapatkan data primer melalui :

1. Observasi, yaitu penulis mengamati langsung proses pengelolaan data kaji cepat dan data logistik serta peralatan yang selama ini berjalan di bagian Bidang Kedaruratan dan Logistik BPBD Provinsi DKI Jakarta.

2. Wawancara (interview), yaitu tanya jawab antara penulis dengan beberapa individu khususnya bagian Bidang Kedaruratan dan Logistik di BPBD yang terlibat langsung dengan data kaji cepat dan data logistik.

\section{Hasil dan Pembahasan}

Perancangan diagram konteks sistem dapat dilihat pada Gambar 1 dengan penjelasan bahwa diagram ini digunakan untuk mengetahui siapa saja user yang terlibat pada sistem usulan yang dibangun. Pada diagram konteks diatas terlihat bahwa terdapat tiga user yang menggunakan system beserta dengan tugas-tugasnya. Admin bertugas menginput data petugas. Sedangkan petugas menginput data data kecamatan, desa, bencana, jenis bencana, korban dan korban_bangunan. Serta pimpinan hanya menerima laporan yang diakses melalui sistem informasi. 


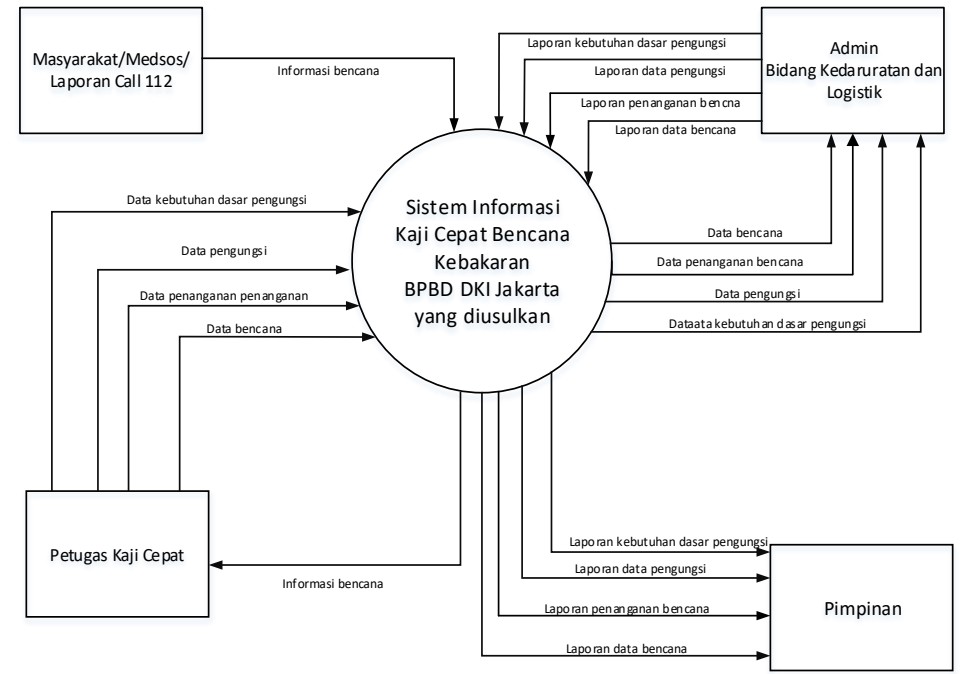

Gambar 1 Diagram Konteks Sistem yang Diusulkan

\section{Hasil Uji Program}

1. Tampilan Menu Login

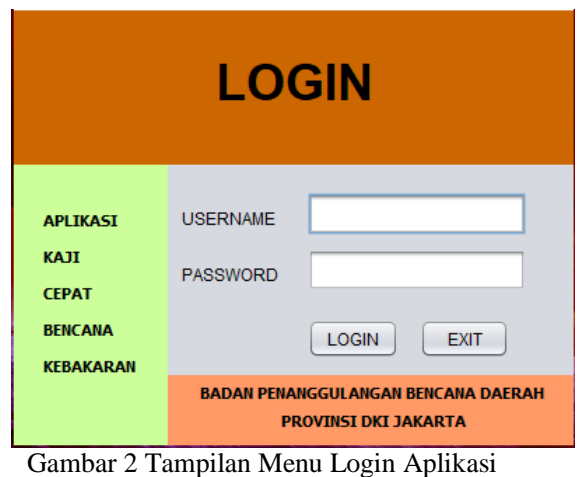

Penjelasan : Tampilan Menu Login berfungsi sebagai akun user agar dapat membuka dan menggunakan aplikasi tersebut.

2. Tampilan Menu Awal

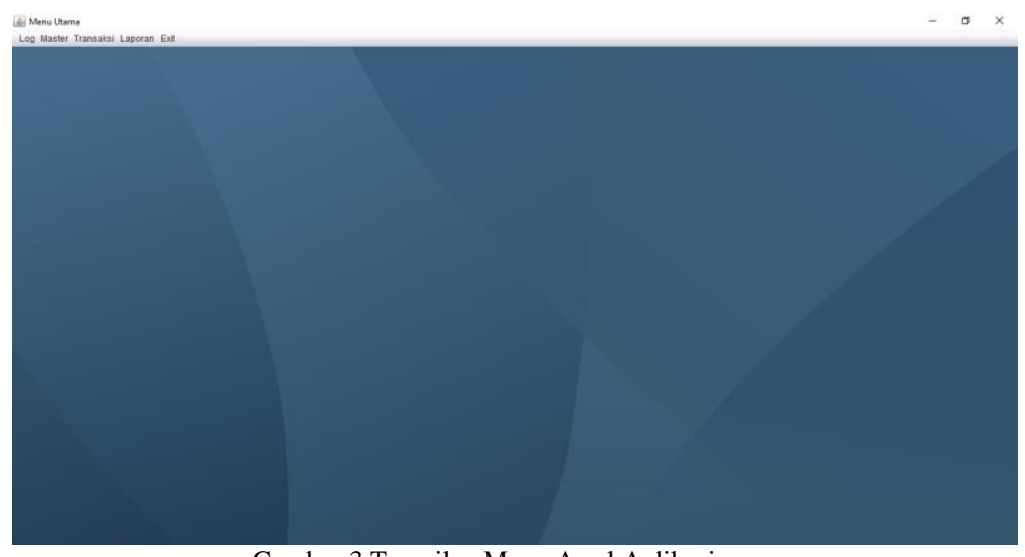

Gambar 3 Tampilan Menu Awal Aplikasi

Penjelasan : Tampilan Menu Utama merupakan tampilan utama yang ditampilkan setelah user berhasil login.

3. Tampilan Menu Data User 


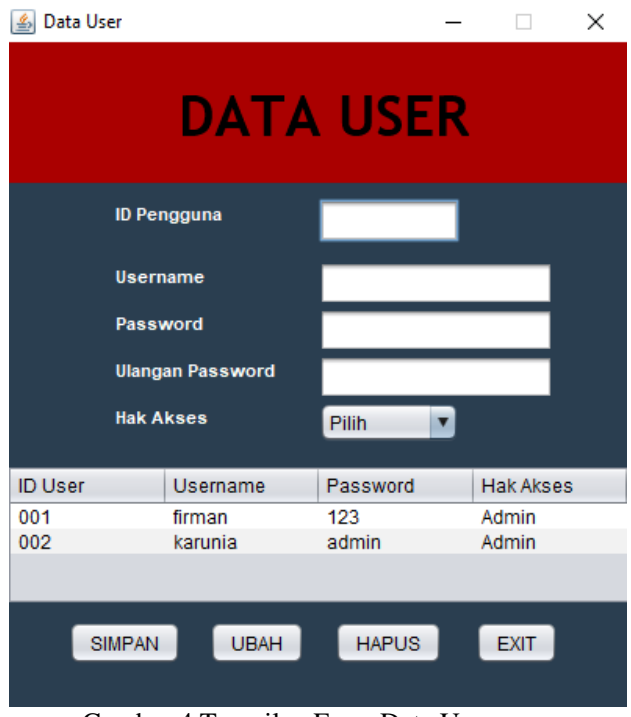

Gambar 4 Tampilan Form Data User

Penjelasan : Tampilan menu data user merupakan tampilan yang digunakan untuk mengolah data petugas, dimana fungsi yang terdapat pada menu ini diantara input data user baru, simpan data user, ubah data user, hapus data user.

4. Tampilan Menu Data Pengungsi

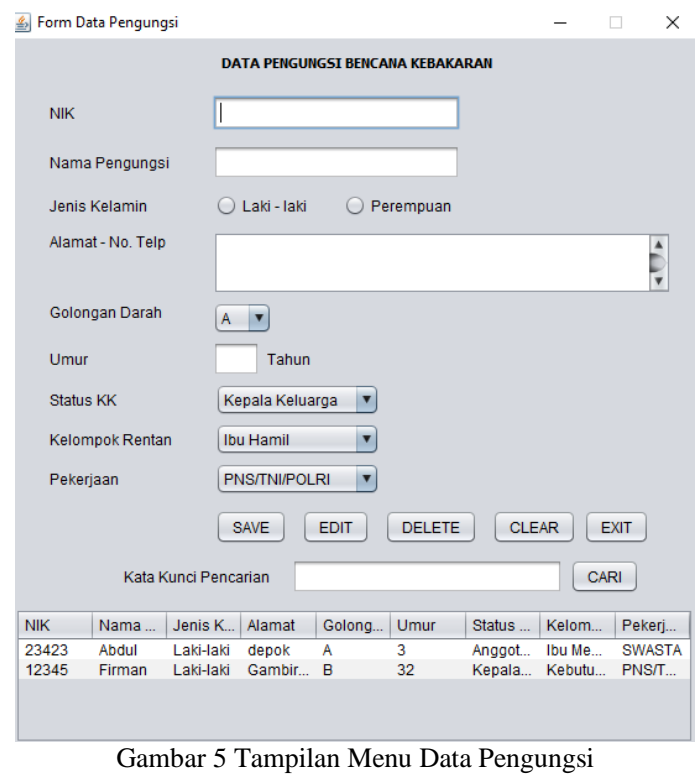

Penjelasan : Tampilan menu data pengungsi digunakan untuk menginput banyaknya pengungsi yang ada di tempat pengungsian akibat bencana kebakaran yang terjadi.

5. Tampilan Form Data Bencana Kebakaran

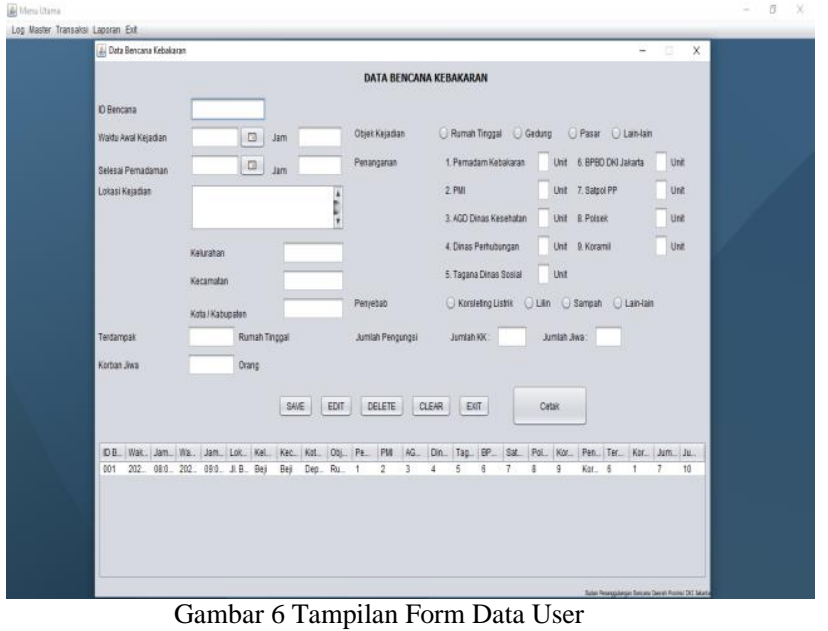


Penjelasan : Tampilan Form Data Bencana Kebakaran merupakan form transaksi yang digunakan untuk menginput bencana kebakaran yang terjadi. Form ini memuat data kejadian, jumlah terdampak akibat kebakaran dan data penanganan kebakaran.

6. Tampilan Form Data Kebutuhan Dasar Pengungsi

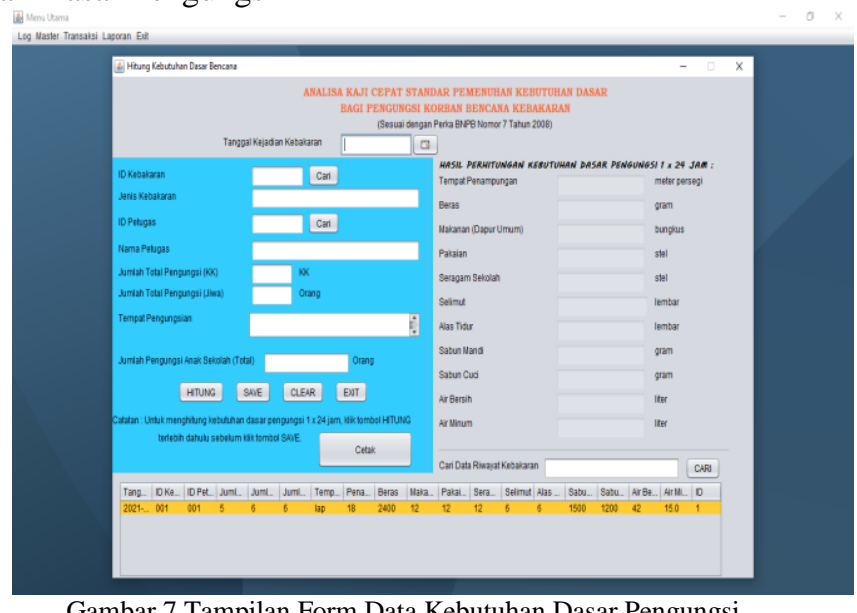

Gambar 7 Tampilan Form Data Kebutuhan Dasar Pengungsi

Penjelasan : Tampilan Form Data Kebutuhan Dasar Pengungsi merupakan form yang digunakan untuk menghitung jumlah kebutuhan dasar pengungsi dengan memasukkan jumlah pengungsi berupa data KK dan jiwa, form ini akan otomatis untuk menghitung kebutuhan dasar pengungsi.

7. Tampilan Rekap Laporan Data Pengungsi

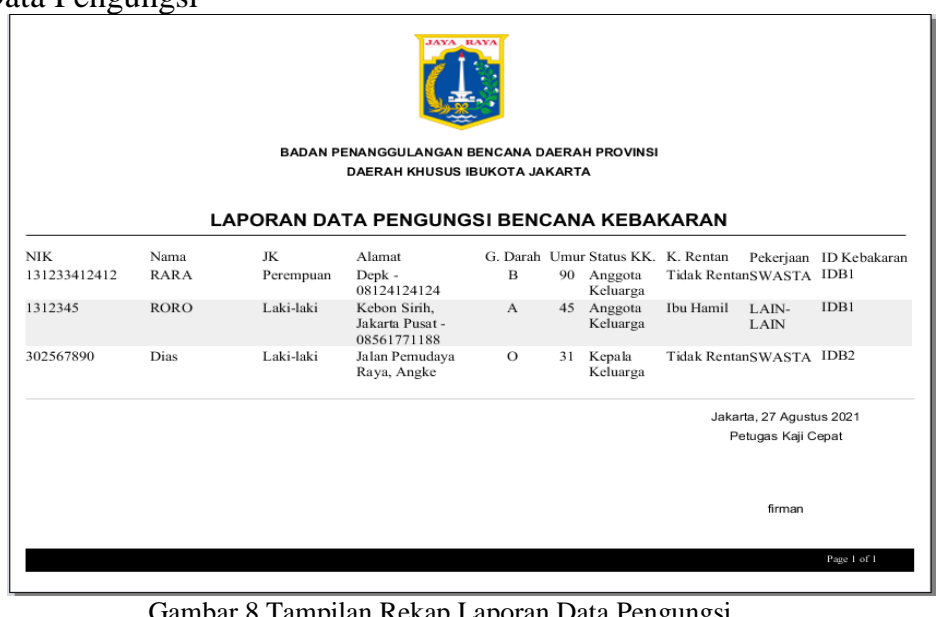

Penjelasan : Rekap Laporan Data Pengungsi ini merupakan hasil cetakan rekapitulasi keseluruhan data pengungsi dari gabungan kebakaran yang telah terjadi.

8. Tampilan Rekap Laporan Data Kebakaran

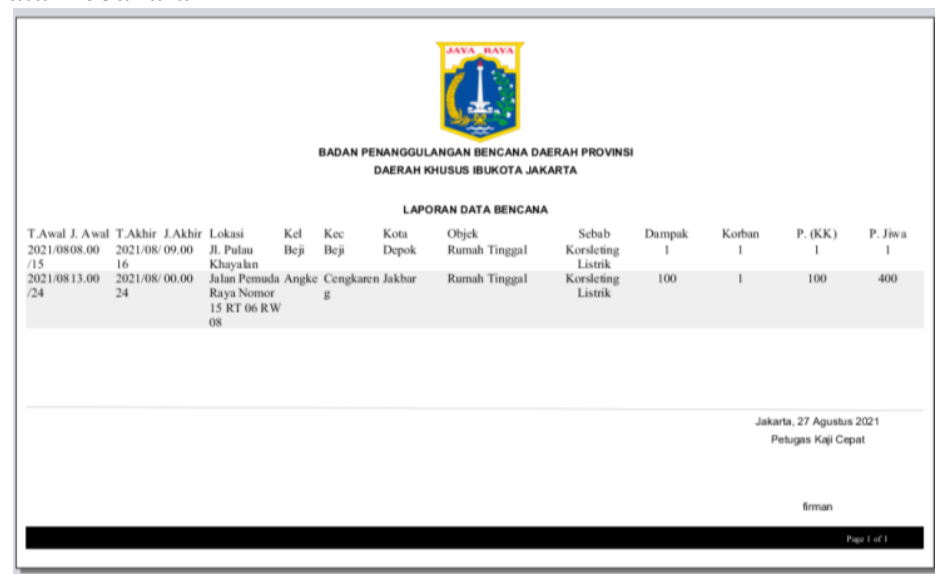

Gambar 9 Tampilan Rekap Laporan Data Kebakaran

Penjelasan : Rekap Laporan Data Kebakaran ini merupakan hasil cetakan rekapitulasi keseluruhan data kebakaran dari gabungan kebakaran yang telah terjadi.

doi: https://doi.org/10.37859/coscitech.v2i2.2949 
9. Tampiran Rekap Laporan Kebutuhan Dasar Pengungsi

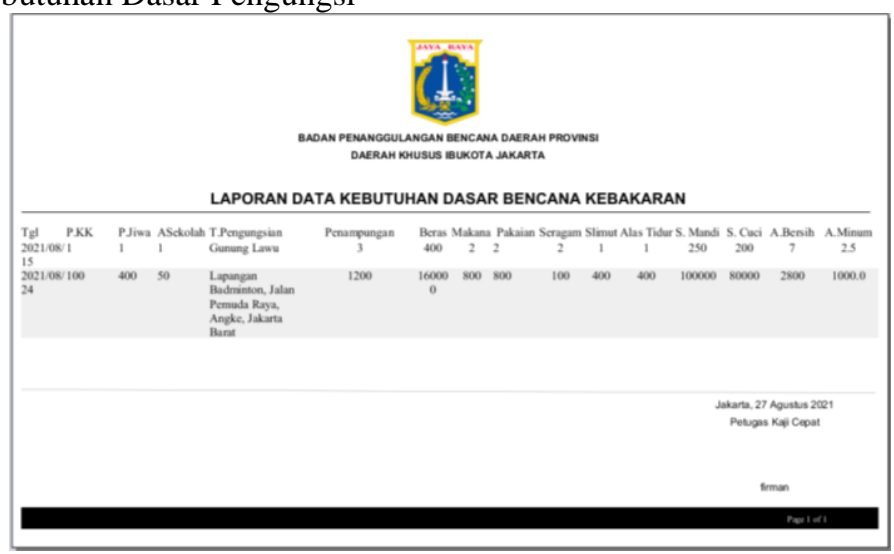

Gambar 10 Tampilan Rekap Laporan Kebutuhan Dasar Pengungsi

Penjelasan : Rekap Laporan Data Kebutuhan Dasar Pengungsi ini merupakan hasil cetakan rekapitulasi keseluruhan data hitung kebutuhan dasar pengungsi dari gabungan kebakaran yang telah terjadi.

10. Tampilan Rekap Laporan Penanganan Bencana

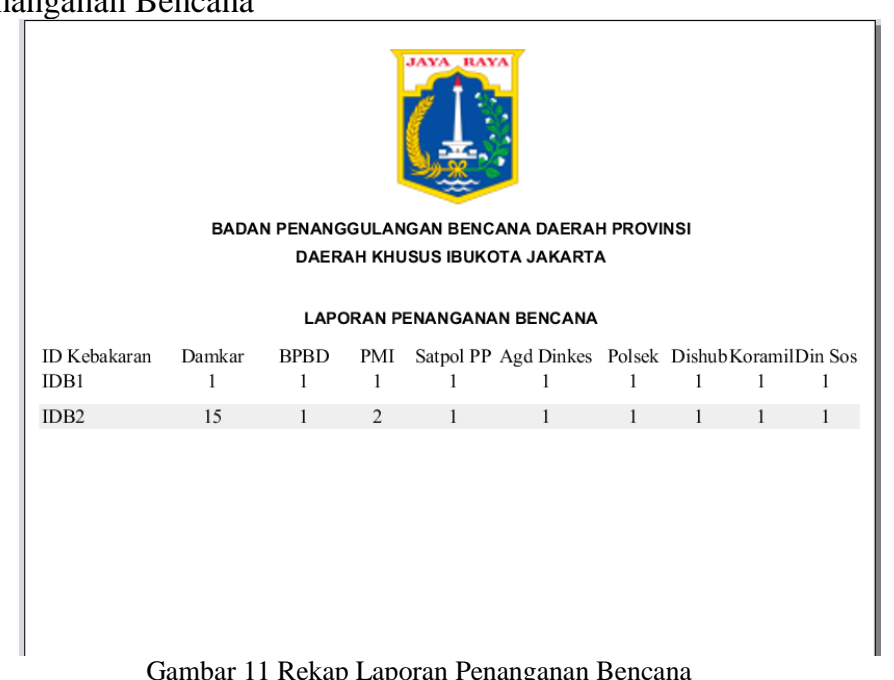

Penjelasan : Rekap Laporan Penanganan Bencana ini merupakan hasil cetakan rekapitulasi keseluruhan data penanganan kebakaran dari gabungan kebakaran yang telah terjadi.

11. Tampilan Cetak Data Pengungsi

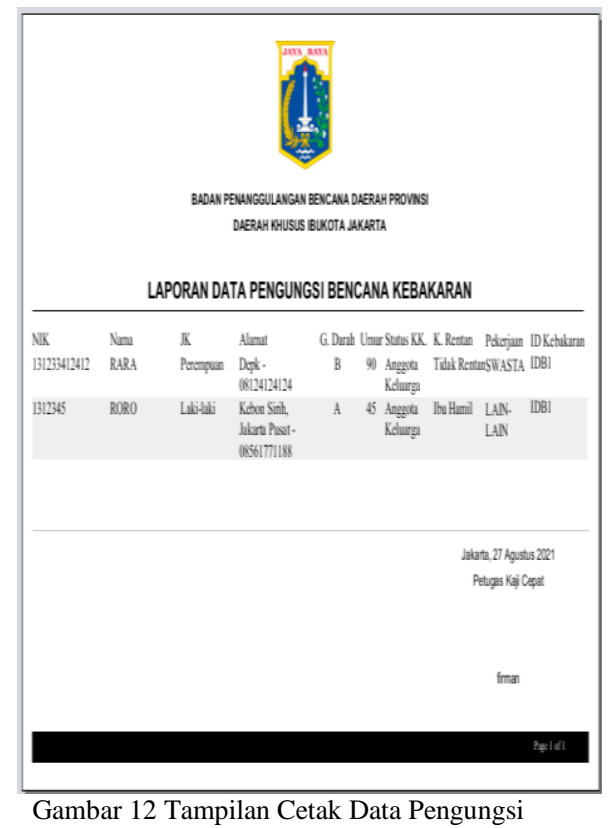


Penjelasan : Cetak Data Pengungsi merupakan laporan hasil cetak data pengungsi dari 1 jenis kejadian kebakaran.

12. Tampilan Cetak Data Kebakaran

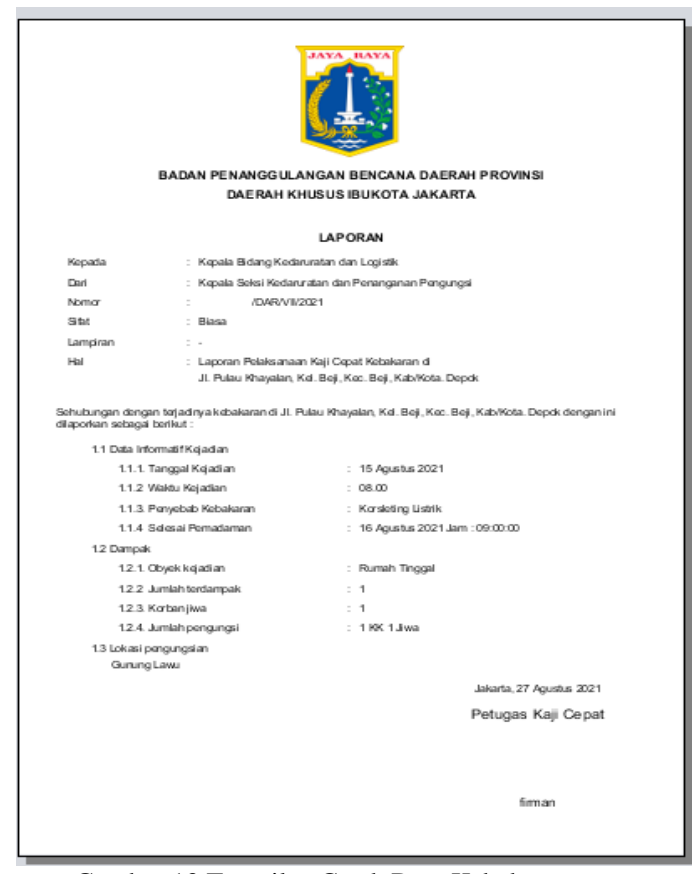

Gambar 13 Tampilan Cetak Data Kebakaran

Penjelasan : Cetak Data Kebakaran merupakan laporan hasil cetak data bencana kebakaran dari 1 jenis kejadian kebakaran. 13. Tampilan Cetak Kebutuhan Dasar Pengungsi

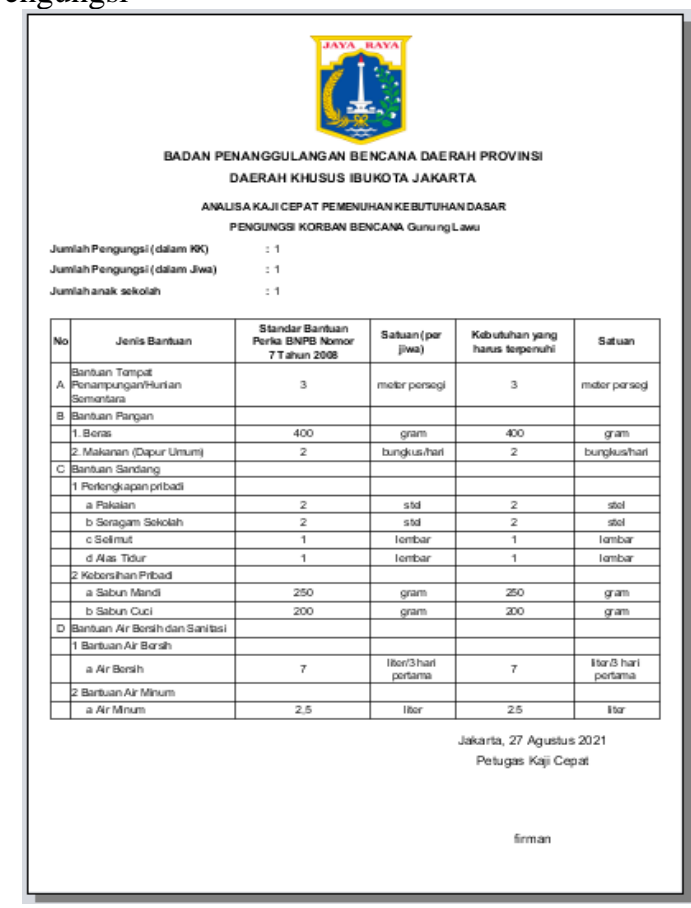

Gambar 14 Tampilan Cetak Kebutuhan Dasar Pengungsi

Penjelasan : Cetak Data Hitung Kebutuhan Dasar Pengungsi merupakan laporan hasil cetak data hitung kebutuhan dasar pengungsi dari 1 jenis kejadian kebakaran.

\section{KESIMPULAN}

Dengan dibuatnya sistem informasi kaji cepat bencana kebakaran Badan Penanggulangan Bencana Daerah Privinsi DKI Jakarta dengan menggunakan Java Netbeans, penulis mempunyai simpulan sebagai berikut : 
1. Sistem informasi kaji cepat kejadian kebakaran yang dibangun penulis dapat memberikan kemudahan dalam hal pengolahan data kebencanaan kebakaran secara cepat dan tepat dibandingkan dengan sistem sebelumnya yang masih menggunakan sistem manual.

2. Sistem informasi ini juga memberikan perhitungan otomatis yang memudahkan dalam memproses pemenuhan kebutuhan dasar korban bencana kebakaran.

3. Sistem informasi ini juga mampu menghasilkan laporan kejadian kebakaran diantaranya laporan data bencana, laporan data pengungsi, laporan perhitungan kebutuhan dasar dan laporan data penanganan bencana kebakaran.

\section{Daftar Pustaka}

[1] Abdul Syah Lamahamu, Subhan (2018). Perancangan Sistem Informasi Pengolahan Data Korban Bencana pada Badan Penanggulangan Bencana (BPBD) Kota Ternate, Volume 1 (No.2). Diakses pada 18 Januari 2020, dari Akademisi Ilmu Komputer Ternate.I. N. Sari, "Rancang Bangun Aplikasi Game Edukasi Pakaian Adat Suku Batak 'Ulos’ Pada Platform Android,’ Univ. Udayana, 2015.

[2] Al-Bahra, Ladjamudin. 2015. Analisis Dan Desain Sistem Informasi. Yogyakarta : Graha Ilmu.

[3] Indriasari, Theresia Devi, Kusworo Anindito, Eddy Julianto (2014). Analisis dan Perancangan Sistem Pengumpulan Data Bencana Alam. Diakses pada 18 Januari 2020, dari Universitas Atma Jaya Yogyakarta.

[4] Indriasari, Theresia Devi, Kusworo Anindito, Eddy Julianto (2014). Analisis dan Perancangan Sistem Pengumpulan Data Bencana Alam. Diakses pada 18 Januari 2020, dari Universitas Atma Jaya Yogyakarta.

[5] Kadir Abdul. 2013. Pemrograman Database MySql Untuk Pemula. Yogyakarta : MediaKom.

[6] Mardiani, Eri, dkk. 2019. Membuat Aplikasi Inventory dengan Java Netbeans, MySql dan iReport. Jakarta : PT. Elex Media Komputindo.

[7] Puspitasari, Januar Ratih. 2005. Sistem Informasi Pengelolaan Data Korban Bencana Alam Pada Kantor Badan Penanggulangan Bencana Daerah (BPBD) Kabupaten Pati. Skripsi. Program Sarjana Universitas Muria Kudus.

[8] Setiawan, Rubi, Dede Kurniadi, H. Bunyamin (2017). Perancangan Sistem Pengelolaan Penanggulangan Bencana Alam Garut Berbasis Sistem Informasi Geografis. Diakses pada 18 Januari 2020 dari Sekolah Tinggi Teknologi Garut.

[9] Soeherman, Bonnie, dan Marion Pinontoan. Designing Information System. Jakarta : PT. Elex Media Komputindo.

[10] Supriyatno. 2010. Pemrograman Database Menggunakan Java \& MySQL untuk Pemula. Jakarta : Mediakita.

[11] Tim Penyusun. 2018. Pedoman Penulisan Skripsi/Tugas Akhir. Jakarta : Universitas Indraprasta PGRI Jakarta.

[12] Ulum, Muhamad Bahrul (2017). Perancangan Sistem Informasi Manajemen Bencana Alam, Volume 14 (Nomor 2). Diakses pada 18 Januari 2020, dari Universitas Esa Unggul Jakarta.

[13] Ulum, M. Chazienul. 2014. Manajemen Bencana (Suatu Pengantar Pendekatan Proaktif. Malang : Universitas Brawijaya Press (UB Press).

[14] Yunita, Farida (2021). Sistem Informasi Pengolahan Data Bencana Alam Provinsi Lampunb Berbasis Web, Vol. 2 (No.1). Diakses pada 18 Januari 2020, dari STMIK Bina Patria.

[15] Zulfan, Bahagia dkk (2017). Sistem Informasi Data Korban Kebencanaan Berbasis Web, Volume 1 (hlm.110-113). Diakses pada 18 Januari 2020, dari Universitas Serambi Mekkah Aceh. 